\title{
S
}

Research article

2021 | Volume 9 | Issue 3 | Pages 78-85

\section{ARTICLE INFO}

Received

June 14, 2021

Revised

August 16, 2021

Accepted

August 18, 2021

Published

September 19, 2021

*Corresponding author Muhammad Faheem Akhtar

E-mail

faheem_dear@hotmail.com

Keywords

Age of maturity

Morphological changes

Seminiferous tubules

Yangzhou ganders

How to cite

Akhtar MF, Ahmad E, Shafiq

IA. Age related alterations in testicular histoarchitecture of

Yangzhou goose ganders. Sci

Lett 2021; 9(3):78-85

\section{Open Access}

\section{Age-Related Alterations in Testicular Histoarchitecture of Yangzhou Goose Ganders}

\author{
Muhammad Faheem Akhtar ${ }^{1 *}$, Ejaz Ahmad², Muhammad Shafiq ${ }^{3}$, \\ Ilyas $\mathrm{Ali}^{4}$ \\ 1 Jiangsu Province Key Laboratory for Molecular and Medical Biotechnology, College of \\ Life Science, Nanjing Normal University, 210023, Nanjing, China \\ 2 Department of Clinical Sciences, Faculty of Veterinary Sciences, Bahauddin Zakariya \\ University, 60800, Multan, Pakistan \\ 3 Department of Cell Biology and Genetics, Shantou University Medical College, \\ Shantou, Guangdong, China \\ ${ }^{4}$ College of Animal Science and Technology, Nanjing Agricultural University, 210095, \\ Nanjing, China
}

\section{Abstract}

The age of maturity and seasonality are vital characteristics in the production of seasonal breeders like Yangzhou ganders. Ancestors of the current geese breeds were wild geese that adapted their breeding season, according to the season having plenty of food and suitable weather conditions to reproduce and raise their chicks to combat harsh environmental conditions. The present study aimed to elucidate histological changes in testicular histoarchitecture of Yangzhou goose ganders. Testis samples were collected from Yangzhou ganders during premature, transition and mature states. Testicular regression was accessed by observing changes in the number of spermatocytes, spermatogonia, elongated spermatids, round spermatids, width of seminiferous tubules, epithelial height, luminal tubular diameter and Johnsen's score. The results depicted a positive correlation between age and number of spermatogonia, primary spermatocytes, spermatids, and epithelial height. Thus, testicular histoarchitecture works usually on the balance between Sertoli and other germ cells. Further, our results conclude that breeding seasonality and age of sexual maturity also affect spermatogenesis efficiency in Yangzhou ganders. 


\section{Introduction}

Compared to other bird species, domestic geese are seasonal breeders with low reproductive efficiency [1]. In ganders, there is a significant alteration in testicular histology among breeding and nonbreeding seasons [2]. Seasonal reproduction in birds and mammals occurs as a result of numerous endocrine and outer environmental interactions, and among all of them, daily photoperiod is unavoidable [3, 4]. The current knowledge of variations in the seminiferous epithelium of nonpasserine birds needs attention. Compared to mammals, there exists a gap in literature elucidating the changes in the seminiferous epithelium in birds. There has been a long debate on factors affecting the normal development of reproductive characteristics in avian species. The age of maturity and seasonality of breeding seem to be key factors of testes' development. Among mammals and birds, physiological and seasonal reproductive alterations occur as a consequence of crosslinks between different endocrine and environmental changes and daily photoperiod remains centered [3, 4]. Hypothalamic gonadotropin-releasing hormone $(\mathrm{GnRH})$, i.e., GnIH-I, follicle-stimulating hormone (FSH) and luteinizing hormone (LH) from anterior pituitary [5] and gonads (testicles and ovaries) keeps endocrine balance [6]. Receptors on Leydig cells can bind with LH and testicular interstitial cells and support androgen secretion (particularly testosterone) from Leydig cells. FSH binds with Sertoli cells, which frame a suitable microenvironment for spermatogenesis [6]. GnRH is secreted from the hypothalamus in a rhythmic pulsatile manner [7]. The pulsatile release of $\mathrm{LH}$ and FSH is predominantly affected by GnRH [8]. Sertoli and Leydig cells are two inevitable germ cells for the normal propagation and functioning of spermatogenesis. For example, Sertoli cells sustained Leydig cell numbers and smooth muscles of the seminiferous epithelium in mature mouse testes [9]. Nurse cells and other germ cells (spermatogonia, spermatocytes) are present inside seminiferous epithelium of testes [10]. Sertoli cells are also called nurse cells because other germ cells are embedded inside Sertoli cells during their developmental stages, i.e., from single spermatogonia to motile spermatid and gets nourishment from Sertoli cells. In rodents, Sertoli cells are present both in peritubular and perivascular compartments of fetal testes and adult
Leydig cells arise from them [11]. Seasonal photoperiodic changes alter reproductive and endocrine regulations of birds and concomitant changes occur with the season and age of maturity in the histological architecture of testes [12, 13].

Yangzhou goose (Anser domesticus) is a genetically engineered goose breed in China [13]. The age of sexual maturity in Yangzhou goose ganders is 227 days [13]. Its egg-laying starts in autumn, peaks between February and March and ends between May and June [14]. Domestic geese are seasonal breeders with lower reproductive efficiency [15]. A comparison of testosterone concentration in Yangzhou ganders was published in our previous research [16] and egg-laying rate in Yangzhou geese was published by other researchers [17]. In ganders, approximately after two months, sublime efficiency in reproduction declines gradually to poor mating activity and semen quality [18]. Ganders' testicular morphometry concomitantly changes with breeding season and non-breeding seasonality. Thus, the purpose of the current study was to check the impact of age of sexual maturity in testicular histological changes of Yangzhou goose ganders with specific changes in testes volume, seminiferous epithelium height, diameter, round spermatids, elongated spermatids, spermatogonia and Sertoli cell numbers.

\section{Materials and Methods}

\section{Ethics statement}

Experimental methods were endorsed by the College Laboratory of Animal Care and Use Committee, Nanjing Agricultural University, China (Approval Numbers: 31572403 and 31402075).

\section{Experimental site and birds' management}

The experiment was performed at a poultry breeding farm $\left(119^{\circ} 58^{\prime} \mathrm{E}, 31^{\circ} 48^{\prime} \mathrm{N}\right)$ affiliated to the Jiangsu Academy of Agricultural Sciences, Changzhou, Jiangsu, China. Thermal reading varies between $0-32^{\circ} \mathrm{C}$ in winter and summer seasons. Precipitation is normal with annual rainfall varying from $1000-1100 \mathrm{~mm}$ with the highest in June-July each year. A total of 30 Yangzhou ganders was selected and tags were attached inside the wings to differentiate them. From the start to the end of experiment, ganders were put at the average temperatures amidst 25$32^{\circ} \mathrm{C}$. Ganders were housed in the semi-controlled 
farm having a vulnerable approach to drinking water and feed. The photoperiod regime was maintained 11L:13D throughout the experiment.

\section{Testis tissue collection}

Testis tissues were collected at 181, 200 and 227 days of age because in Yangzhou ganders, there exist differences in testes maturation and body maturation. Sexual maturity in Yangzhou ganders is 227 days of age [13]. Initially, after 181 days of age, ten ganders from both groups were slaughtered for testes samples. Similarly, ten ganders from both groups were slaughtered after 200 and 227 days of age. Instantly after collection, samples were kept in liquid nitrogen and stored at $-80^{\circ} \mathrm{C}$ for further analysis.

\section{Microscopic analysis}

A small piece of left testis tissue $\left(0.125 \mathrm{~cm}^{3}\right)$ from each bird was taken, put in $10 \% \mathrm{CH}_{2} \mathrm{O}$ solution and it was prepared for histological evaluation by utilizing a common tissue processor (LEICA RM 2235). Then testes slices were dried in $\mathrm{C}_{2} \mathrm{H}_{5} \mathrm{OH}$ in ascending dilutions, i.e., $70 \%, 80 \%, 90 \%$ and $100 \%$, and then accordingly washed in $\mathrm{C}_{8} \mathrm{H}_{10}$ and fixed in paraffin wax. Testes tissues $(5 \mu \mathrm{m})$ were cut horizontally, spread on glass slides, and colored with hematoxylin and eosin (H\&E). Colored testes' slides were observed under a light microscope (Olympus, BX63) at $10 \times$ and $40 \times$ magnification to observe alterations in the diameter of seminiferous tubules and germ cell numbers. Sertoli cells were analyzed according to Hess and França [19], while spermatogonium was characterized by chromosomal changes [20, 21]. Spermatogonia, spermatocytes were analyzed based on comparative size, shape and nuclear morphology. Analysis of the different growth stages of the seminiferous tubules was classified by observing histological alterations in the germ cell developmental stages and cellular associations. seminiferous epithelium height was measured by taking the average of two longitudinal opposed measures $\mathrm{EH} 1$ and $\mathrm{EH} 2$. While the luminal tubular diameter was determined by the difference between the total diameter (TD) and the sum of both measures of the epithelium height $(\mathrm{EH} 1+\mathrm{EH} 2)$. Ten morphological sections were counted from each treatment by Image $\mathbf{J}$ software [22].

\section{Score for variations in seminiferous epithelium}

Spermatogonium, spermatocytes and spermatids development in the seminiferous tubules were classified by following Johnsen's scores:

$10=$ seminiferous epithelium with spermatogonia, spermatocytes and spermatids

$9=$ spermatozoa present with random appeared spermatogenesis

$8=$ few spermatozoa

$7=$ no spermatozoa, but spermatids present

$6=$ few spermatids present

$5=$ only primary and secondary spermatocytes

$4=$ some spermatocytes

$3=$ spermatogonia present

$2=$ only Sertoli cells

$1=$ almost empty lumen

The mean score was analyzed by selecting 10 seminiferous tubules/birds.

\section{Statistical analysis}

Statistical analysis was observed with SPSS (Version 20.0) and Graph Pad Prism (Version 5.0). Measurements were shown as the mean \pm standard error of the mean (SEM). Alterations among treatments were determined with a one-way analysis of variance (ANOVA), followed by Turkey's post hoc test and two-way ANOVA by considering Bonferroni post-tests to compare the means of the replicates, where the significance level (p) was fixed at 0.05 .

\section{Results}

\section{Testicular development and volume}

On day 181, testes were smaller in size but as moving towards maturity, a substantial increase in testes size and volume was observed on day 200 . While on day 227 , testes were fully matured in size. There was a marginal transition in testicular size and volume from $200 \mathrm{~mm}^{3}$ on day 181, $400 \mathrm{~mm}^{3}$ on day 200 and $600 \mathrm{~mm}^{3}$ on 227 days of age. Testicular development can be seen in Fig. 1 on days 181, 200 and 227 of age.

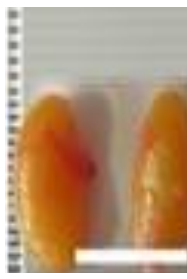

Premature

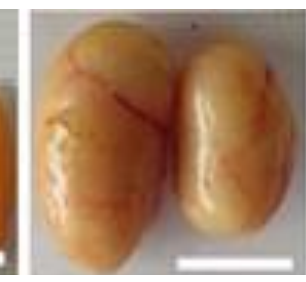

Transition

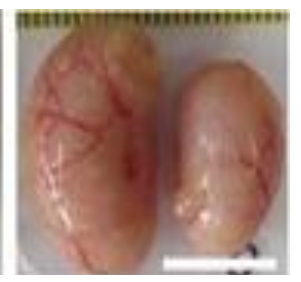

Mature
Fig. 1 Paired testes of Yangzhou ganders at premature, transition and mature stages after 181, 200 and 227 days of age, respectively; Scale bar $=5 \mathrm{~mm}$. 
(a)

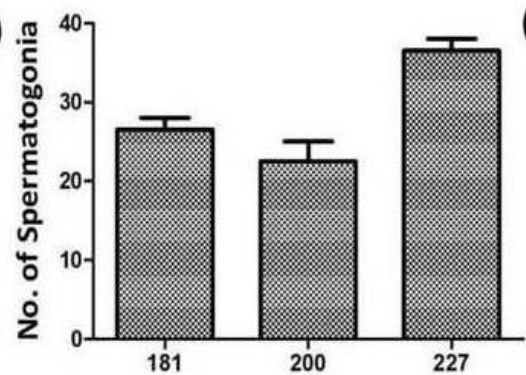

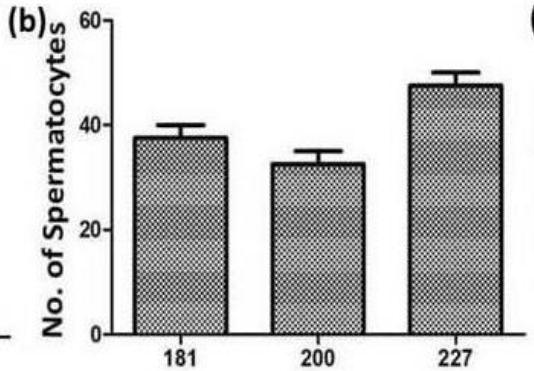
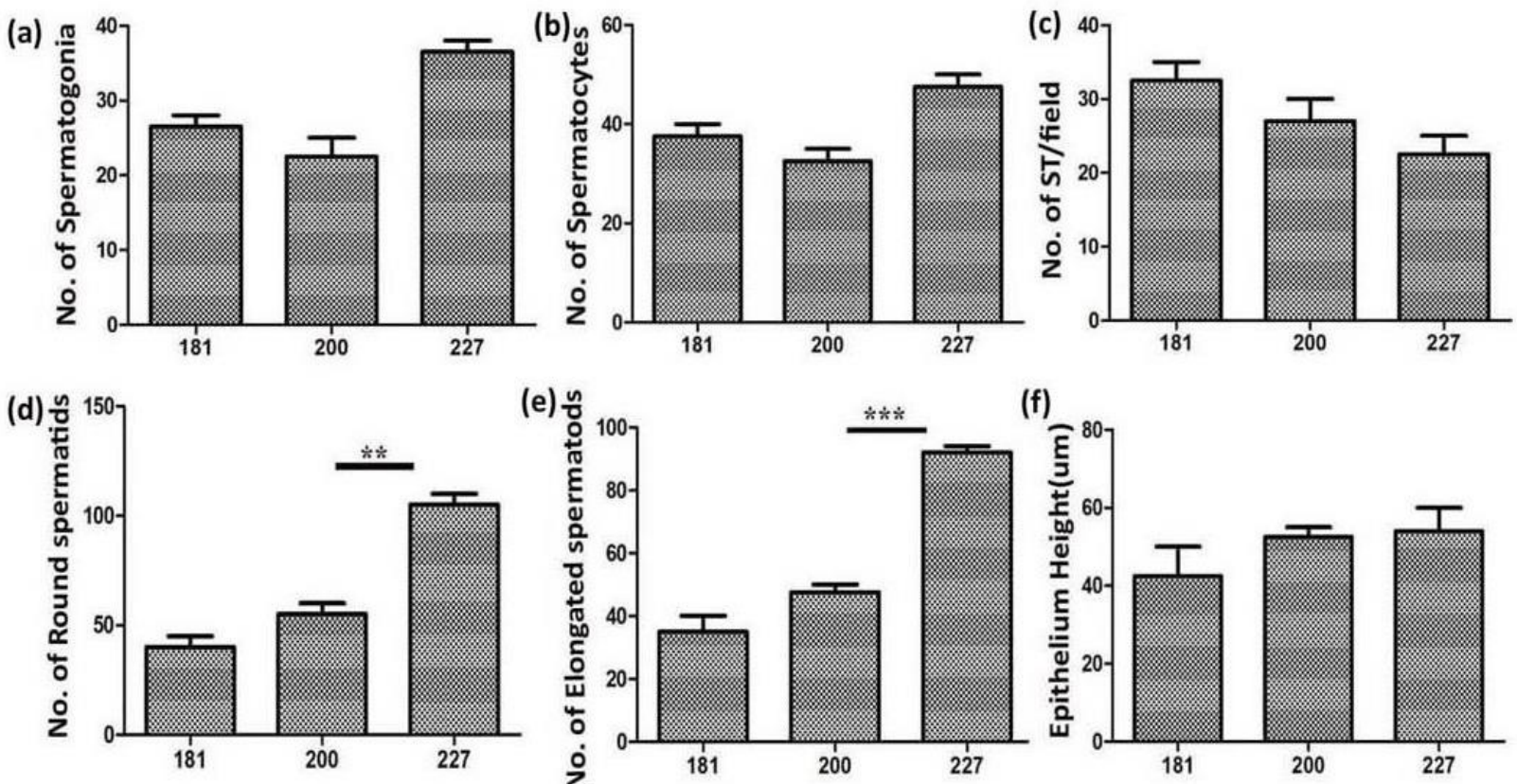

(e) 늠
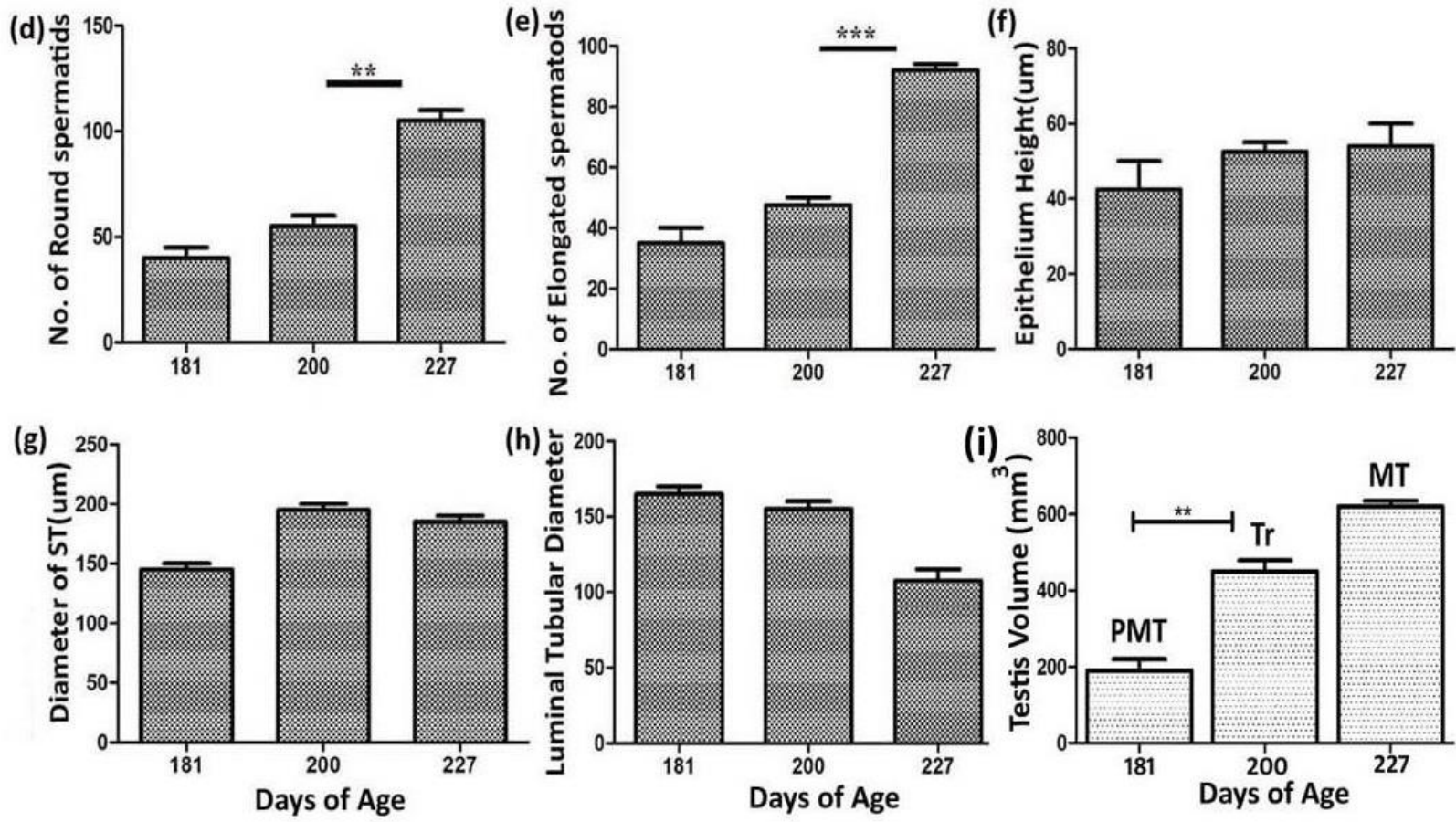

Fig. 2 Histological parameters depicting (a) spermatogonia numbers; (b) spermatocytes; (c) seminiferous tubules per field; (d) number of round spermatids; (e) number of elongated spermatids; (f) epithelium height ( $\mu \mathrm{m})$; (g) diameter of seminiferous tubules $(\mu \mathrm{m})$; (h) luminal tubular diameter and (i) testes volume $\left(\mathrm{mm}^{3}\right)$. Each bar is the mean value of six replicates. Symbol (*) indicates statistical significance difference at $P<0.05$.

Number of germ cells, epithelial height, seminiferous tubules and luminal tubular diameter

Germ cells were counted, and mean values were analyzed. As the testes move from premature state to transition state, an increase in the number of germ cells, epithelial height, seminiferous tubules diameter and luminal tubular diameter was determined, except number of seminiferous tubules per field that showed a decrease compared to all other parameters (Fig. 2). The elevated number of germ cells are in accordance with testicular development and volume enhancement. Fig. 3 shows histological sections of seminiferous tubules on days 181,200 and 227 of age at $10 \times$ and $40 \times$ magnifications. With increase in age, there was a concomitant ascending pattern in diameter of seminiferous tubules.

\section{Johnson's score}

Johnsen's score was analyzed according to above mentioned criteria. Birds' testes were immature on day 181, so got low Johnsen's score. It elevated as the bird moved from premature state of testis development to transition state and mean score at this stage was around 7 although there were sections of seminiferous tubules having empty lumen as shown in representative histological pictures at 200 days of age. The highest Johnsen's score was determined at 227 days of age when the testes were fully developed and in perfect state of spermatogenesis. 

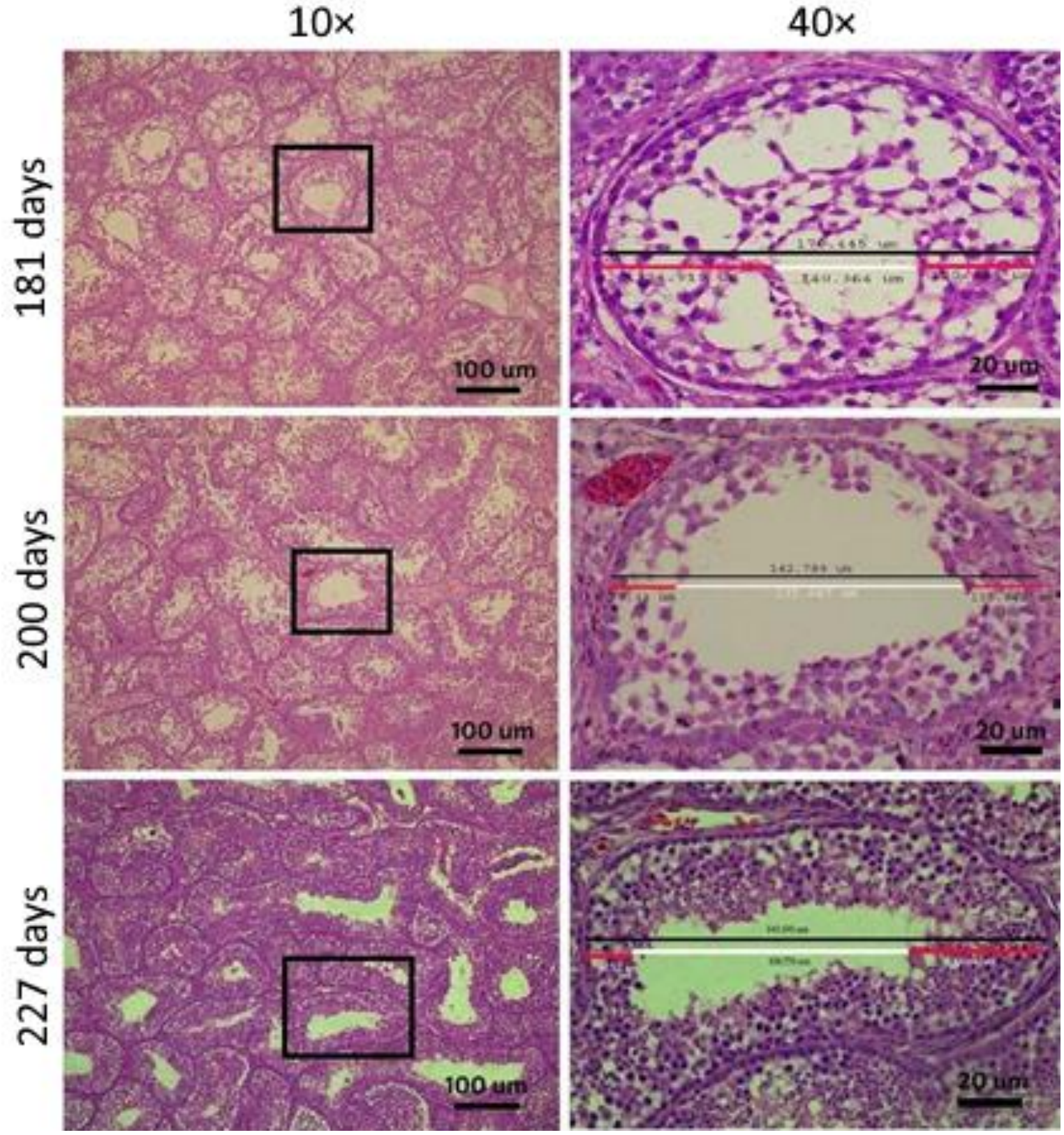

Fig. 3 Histological measurement of various seminiferous tubules parameters, i.e., seminiferous tubules width, luminal tubular diameter, epithelial heights in Yangzhou ganders after 181, 200 and 220 days of age. All measurements are in $\mu$ m. Scale bars represent $100 \mu \mathrm{m}$ at $10 \times$ and $20 \mu \mathrm{m}$ at $40 \times$ magnifications.

\section{Discussion}

The current study is first to elaborate age-related changes in histoarchitecture of Yangzhou ganders' testes from the stage of prematurity to mature testes state, including the number of spermatogonia, spermatocytes, round and elongated spermatids, epithelium height, seminiferous tubules and luminal tubular diameter, testes volume and
Johnsen's score. While moving from an immature to a mature state, testes undergo dramatical histological changes, which could be seen in this study [23-25]. In comparison with mammals, birds generally have both large absolute and particularly relative testes weights [26]. Sperm production is strongly correlated with testicular mass [27]. Thus, we can speculate that until the bird reaches a mature state, there is a crosswalk between various 

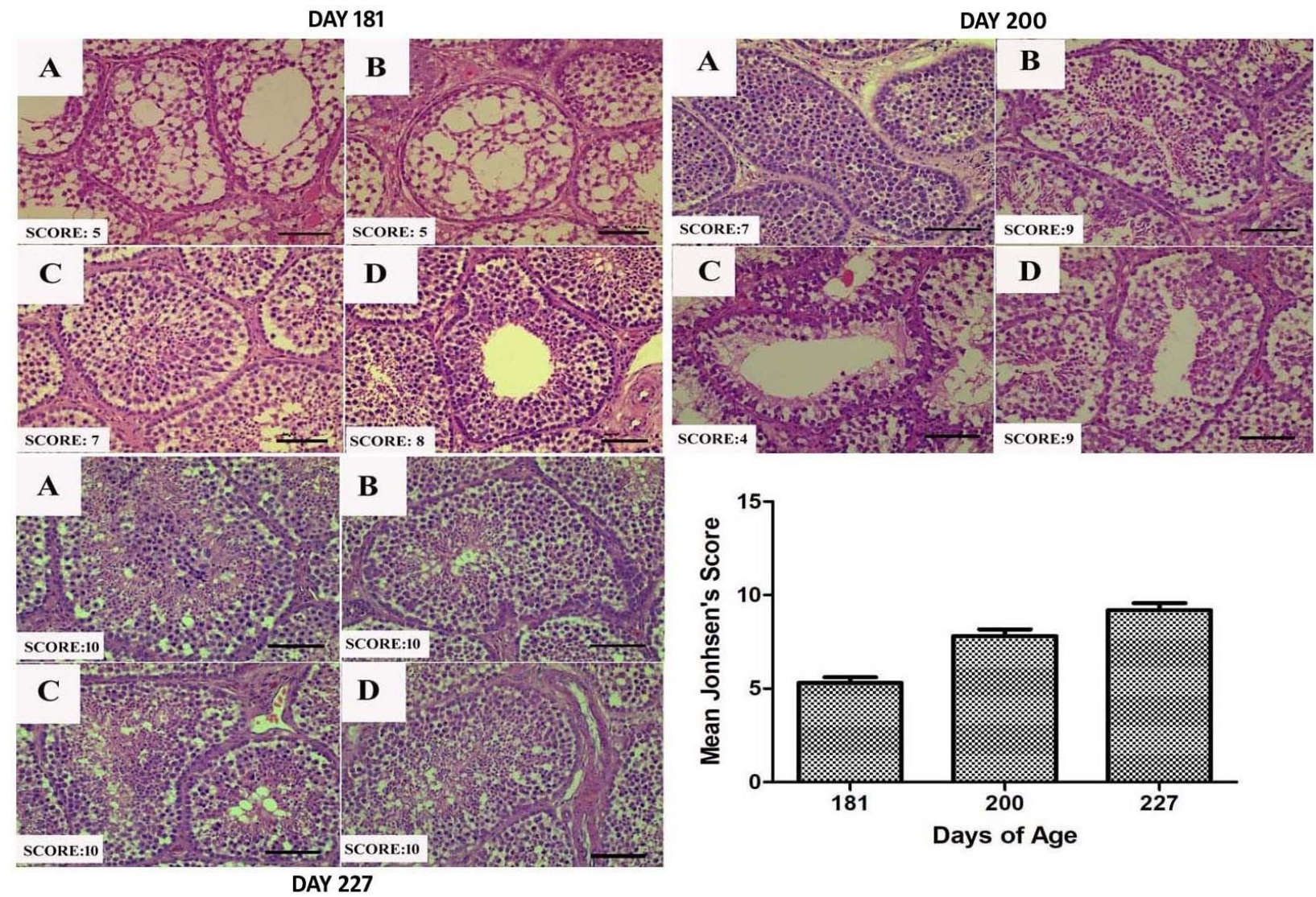

Fig. 4 Histological images depicting measurement of Johnsen's score and mean Johnson's score in testis sections of Yangzhou ganders after 181, 200 and 227 days of age. Scale bar $=20 \mu \mathrm{m}$

testicular histological parameters. In the present study, testicular volume increased from $200 \mathrm{~mm}^{3}$ to $600 \mathrm{~mm}^{3}$ from 181 to 227 days of age, i.e., from premature state to mature state. While from premature state to transition state, change was onefold, i.e., from $200 \mathrm{~mm}^{3}$ to $400 \mathrm{~mm}^{3}$. This swift testis atrophy is concomitant with germ cell numbers except for decrease pattern in luminal tubular diameter. These gross seasonal and agerelated variations in our study are in line with other seasonal bird species that undergo drastic changes [28-31]. In our previous study, we had analyzed testosterone concentration of Yangzhou ganders after 181, 200 and 227 days [16], which was decreased, while testes volume elevated with an increase in the number of days. These findings confirm that Yangzhou ganders belong to the temperate zone having latitude $\left(30-40^{\circ} \mathrm{N}\right)$ and initiate their reproductive seasonality in autumn and finish in the subsequent spring-early summer. In temperate zones, reproduction diminishes by early summer, while testicular size remains small in winter months and testicular recrudescence initiates in spring [32]. Testicular histology varies with breeding stage and age of maturity. In our present study, birds move from premature stage to transition and further to mature testes, various waves in seminiferous epithelium cause variations in seminiferous tubules. Johnsen's score was lower in premature testes, elevated in the transition stage and was highest in the mature stage due to mature testes and perfect state of spermatogenesis [13]. Spermatogonia, spermatocytes, spermatids, epithelial height, and diameter of seminiferous tubules were positively correlated depicting that Yangzhou ganders were moving from premature to mature testis [33]. An elevation in the germ cell numbers in seminiferous tubules was positively correlated to their diameter, lumen diameter and epithelial height [13]. With the advancement of spermatogenic activity, seminiferous tubules per field were declined. On days 181, 200 and 227 of age, mean seminiferous tubules per field were 32 , 27 and 25, respectively, showing an inverse relationship with testes volume, seminiferous tubular diameter, epithelial height and luminal 
tubular diameter [13]. In the present study, measuring Sertoli cell number was beyond the scope. Considering the results of the present study, we can speculate that on 181, 200 and 227 days of age, testes were in preparatory, accelerative and culmination phases, respectively. Furthermore, alterations in testes histoarchitecture confirm our hypothesis.

\section{Conclusions}

In seasonal breeders like Yangzhou ganders, only age is not a factor in testes development, albeit other factors like breeding seasonality, altitude, nutrition are also inevitable regulators. In seasonal breeders, photoperiod is one of the most credible and important environmental factors for reproduction. Furthermore, we can speculate that Sertoli cell development, followed by massive germ cells development and proliferation are responsible for rapid testicular development during breeding season in Yangzhou ganders. For further understanding, changes in testicular histoarchitecture need to be explored after peak breeding season and in mature but resting state of testes.

\section{Funding}

This study was supported by grants of Jiangsu Innovation of Agricultural Science and Technology CX (15)1008, National Natural Science Foundation of China (31372314), China Agriculture Research System (CARS-40-20).

\section{Conflict of Interest}

The authors have no conflict of interest to declare with regards to the publication of this work.

\section{References}

[1] Gumułka M, Rozenboim I. Effect of breeding stage and photoperiod on gonadal and serotonergic axes in domestic ganders. Theriogenology 2015; 84(8):133241.

[2] Leska A, Kiezun J, Kaminska B, Dusza L. Seasonal changes in the expression of the androgen receptor in the testes of the domestic goose (Anser anser $\mathrm{f}$. domestica). Gen Comp Endocrinol 2012; 179(1):6370.

[3] Gwinner E. Circannual rhythms in the control of avian migrations. Adv Study Behav 1986; 16:191228.

[4] Sharp PJ. Photoperiodic control of reproduction in the domestic hen. Poult Sci 1993; 72(5):897-905.

[5] Deviche P, Hurley LL, Fokidis HB. Avian testicular structure, function, and regulation. Hormones and
Reproduction of Vertebrates: Elsevier; 2011. p. 2770.

[6] Jin JM, Yang WX. Molecular regulation of hypothalamus-pituitary-gonads axis in males. Gene 2014; 551(1):15-25.

[7] Seeburg PH, Mason AJ, Stewart TA, Nikolics K, editors. The mammalian GnRH gene and its pivotal role in reproduction. Proceedings of the 1986 Laurentian Hormone Conference; 1987: Elsevier.

[8] Thackray VG, Mellon PL, Coss D. Hormones in synergy: regulation of the pituitary gonadotropin genes. Mol Cell Endocrinol 2010; 314(2):192-203.

[9] Rebourcet D, O'Shaughnessy PJ, Monteiro A, Milne L, Cruickshanks L, Jeffrey N, et al. Sertoli cells maintain Leydig cell number and peritubular myoid cell activity in the adult mouse testis. PloS One 2014; 9(8):e105687.

[10] Wu S, Yan M, Ge R, Cheng CY. Crosstalk between Sertoli and germ cells in male fertility. Trends Mol Med 2020; 26(2):215-31.

[11] DeFalco T, Takahashi S, Capel B. Two distinct origins for Leydig cell progenitors in the fetal testis. Dev Biol. 2011; 352(1):14-26.

[12] Nicholls TJ, Goldsmith AR, Dawson A. Photorefractoriness in birds and comparison with mammals. Physiol Rev 1988; 68(1):133-76.

[13] Akhtar MF, Ahmad E, Mustafa S, Chen Z, Shi Z, Shi F. Spermiogenesis, stages of seminiferous epithelium and variations in seminiferous tubules during active states of spermatogenesis in Yangzhou goose ganders. Animals 2020; 10(4):570.

[14] Shi Z, Tian Y, Wu W, Wang Z. Controlling reproductive seasonality in the geese: a review. World's Poult Sci J 2008; 64(3):343-55.

[15] Shi ZD, Huang YM, Liu Z, Liu Y, Li XW, Proudman $\mathrm{JA}$, et al. Seasonal and photoperiodic regulation of secretion of hormones associated with reproduction in Magang goose ganders. Domest Anim Endocrinol 2007; 32(3):190-200.

[16] Akhtar MF, Wei Q, Zhu H, Chen Z, Ejaz A, Shi Z, et al. The role of active immunization against inhibin $\alpha$ subunit on testicular development, testosterone concentration and relevant genes expressions in testis, hypothalamus and pituitary glands in Yangzhou goose ganders. Theriogenology 2019; 128:122-132.

[17] Zhu H, Chen Z, Shao X, Yu J, Wei C, Dai Z, et al. Reproductive axis gene regulation during photostimulation and photorefractoriness in Yangzhou goose ganders. Front Zool 2017; 14(1):115.

[18] Gumułka M, Rozenboim I. Mating activity of domestic geese ganders (Anser anser f. domesticus) during breeding period in relation to age, testosterone and thyroid hormones. Anim Reprod Sci 2013; 142(3-4):183-90.

[19] Hess RA, França LR. Structure of the Sertoli cell. In: Sertoli Cell Biology; 2005, pp.19-41.

[20] Aire T, Olowo-Okorun M, Ayeni J. The seminiferous epithelium in the guinea fowl (Numida meleagris). Cell Tissue Res 1980; 205(2):319-25.

[21] Alvarenga ÉRd, França LRd. Effects of different temperatures on testis structure and function, with 
emphasis on somatic cells, in sexually mature Nile tilapias (Oreochromis niloticus). Biol Reprod 2009; 80(3):537-44.

[22] Lewis-Johnes D. A modified Johnsen's count for evaluation of spermatogenesis in the rat. IRCS Med Sci $1985 ; 13: 510-1$.

[23] Murton RK. Avian breeding cycles: Oxford University Press, USA; 1977.

[24] Farner D, Follett B. Reproductive periodicity in birds. Horm Evol 1979; 2:829-72.

[25] Gwinner E. Circadian and circannual programmes in avian migration. J Exp Biol 1996; 199(1):39-48.

[26] Clulow J, Jones R. Production, transport, maturation, storage and survival of spermatozoa in the male Japanese quail, Coturnix coturnix. Reproduction 1982; 64(2):259-66.

[27] Moller A. Ejaculate quality, testes size and sperm production in mammals. Func Ecol 1989:91-6.

[28] Hingst O, Blottner S. Quantification of apoptosis (programmed cell death) in mammalian testis by
DNA-fragmentation ELISA. Theriogenology 1995; 44(3):313-9.

[29] Blottner S, Hingst O, Meyer H. Inverse relationship between testicular proliferation and apoptosis in mammalian seasonal breeders. Theriogenology 1995; 44(3):321-8.

[30] Heninger NL, Staub C, Blanchard TL, Johnson L, Varner DD, Forrest DW. Germ cell apoptosis in the testes of normal stallions. Theriogenology 2004; 62(1-2):283-97.

[31] Young KA, Ball GF, Nelson RJ. Photoperiodinduced testicular apoptosis in European starlings (Sturnus vulgaris). Biol Reprod 2001; 64(2):706-13.

[32] Lofts B, Murton R, Thearle R. The effects of testosterone propionate and gonadotropins on the bill pigmentation and testes of the house sparrow (Passer domesticus). Gen Compar Endocrinol 1973; 21(1):202-9.

[33] Jamieson BG. Reproductive biology and phylogeny of birds, part a: Phylogeny, morphology, hormones and fertilization: CRC Press; 2011. 